\title{
Estimación Simultánea de Escenas Deformables y Trayectoria a partir de una Secuencia de Imágenes Monoculares
}

\author{
A. Agudo1, B. Calvo2, J.M.M. Montiel 1 \\ ${ }_{1}$ Grupo de Robótica, Percepción y Tiempo Real (RoPeRT) Instituto de Investigación en Ingeniería de \\ Aragón (I3A) \\ Universidad de Zaragoza, Mariano Esquillor s/n, 50018, Zaragoza, Spain.
}
Tel. +34-976762707, Fax +34-976762043, e-mail:aagudo@unizar.es
${ }_{2}$ Grupo de Mecánica Aplicada y Bioingeniería (AMB).
Instituto de Investigación en Ingeniería de Aragón (I3A)

Universidad de Zaragoza, Mariano Esquillor s/n, 50018, Zaragoza, Spain.

Tel. +34-976762707, Fax +34-976762043

\begin{abstract}
Durante la última década se ha demostrado experimentalmente la posibilidad de realizar reconstrucciones 3D de entornos desconocidos tomando como único dato la secuencia de imágenes que toma una cámara que se mueve con una trayectoria también desconocida. Estos métodos son conocidos como SLAM (Simultaneous Localization And Mapping). Dichos sistemas, asumen que la escena observada es rígida, una hipótesis razonable en ambientes robóticos, tales como interiores de edificios, entornos urbanos y en menor medida entornos exteriores. Sin embargo, dicha hipótesis no se cumple en otras situciones, como por ejemplo, en las escenas médicas de cirugía con endoscopio, en las que los sistemas actuales fallarían. Para abandonar la hipótesis de rigidez, en este trabajo se combinan las ecuaciones de Navier para sólidos deformables, con un EKF (Extended Kalman Filter) para estimar mediante un procesamiento secuencial, la estructura 3D no rígida y el movimiento de la cámara a partir de una secuencia de imágenes monoculares. Las ecuaciones de Navier se resuelven numéricamente mediante el MEF (método de los elementos finitos). Para ello, la estructura observada es discretizada mediante una malla de elementos planos triangulares cuyos nodos se corresponden con los puntos característicos medidos. La metodología es validada experimentalmente utilizando secuencias de imágenes reales de escenas deformables y movimientos de cámara realistas. La propuesta es particularmente relevante para el tratamiento de secuencias médicas adquiridas con endoscopio, permitiendo incorporar la respuesta mecánica de los tejidos ante la aplicación de diferentes acciones.
\end{abstract}

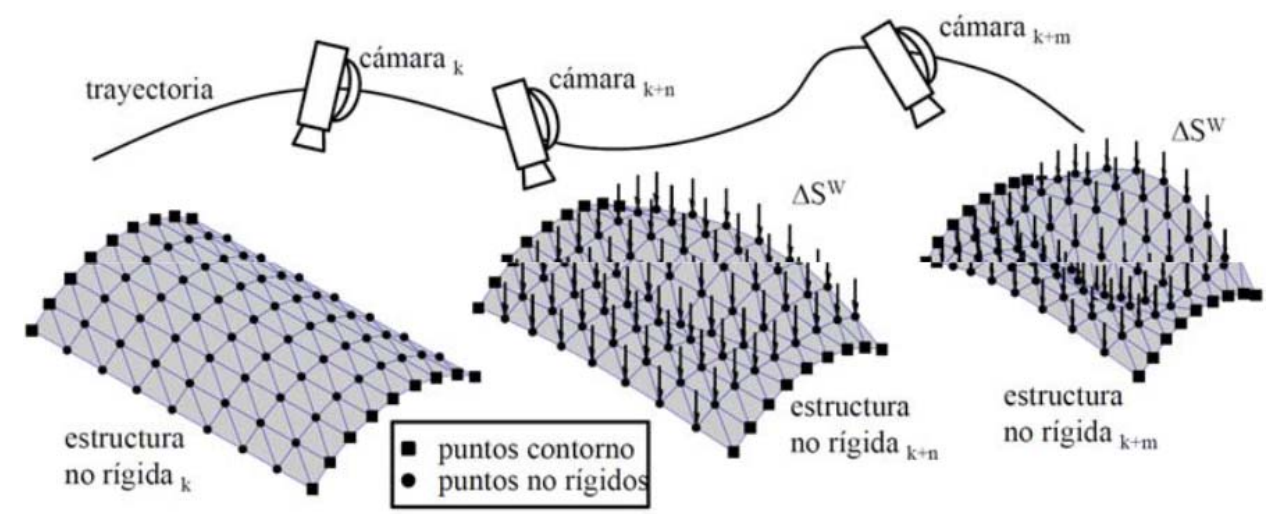

